\title{
Study on the Development Trends and Models of "Internet + Rural Entrepreneurship Education"
}

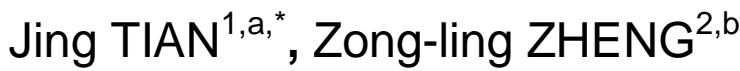 \\ ${ }^{1}$ Faculty of Education, Yunnan Normal University, Kunming 650500, China \\ ${ }^{2}$ Pensioners Office, Yunnan Normal University, Kunming 650500, China \\ ajingtian20032003@163.com, bzling75@yahoo.com.cn \\ *Jing TIAN
}

\begin{abstract}
Keywords: internet + , rural areas, entrepreneurial, training mode
Abstract. Entrepreneurship education is the key of rural development. It is an important part of speeding up the development of modern agriculture, promoting the construction of new socialist countryside and practicing the innovation of agricultural science and technology. In the era of Internet, the rural entrepreneurship education further breakthrough time and space constraints, further personalized, and mode of entrepreneurship education has become more diversified, entrepreneurship education ecological changed more. The influence of cross fusion of Internet + rural entrepreneurship training and entrepreneurial talent training mode was analyzed. Some references and Enlightenment were provided to the rural talents cultivation.
\end{abstract}

\section{Introduction}

"Internet $+"$ as a new type of science and technology revolution in 21 st century, which emphasized the way of thinking that the Internet can be incorporated into the development of traditional industries, and fusion depth of traditional industries and contributed the upgrade to the innovation of the traditional industry. Education is an activity that educators exert influence on education objects. Entrepreneurship education is a new factor in education content along with the rapidly developing of science and technology. The goal of entrepreneurial education is to cultivate social members with entrepreneurial spirit and social elites with entrepreneurial ability. That Internet thinking is Integrated into entrepreneurial education, forming the "Internet + entrepreneurship education" mode is the requirement of the times and the development opportunity of the entrepreneurial education. Rural entrepreneurship education is a social practice, which provided the entrepreneurship practical guidance and technical training, advisory services for rural population based on the local rural reality. Its aims are cultivate the new farmers' entrepreneurial consciousness, entrepreneurial ability and entrepreneurial personality. It can effectively meet the demand of innovation spirit and innovation ability in the knowledge economy era.

\section{Unscramble on "Internet + rural entrepreneurial education"}

\section{"Internet +"}

"Internet + " is the "industrial revolution" that caused by "information revolution". Along with the progress of information technology, everyone can be gain information source of independent in the Internet society. Information propagation mode has been rapid development in the direction of the point to point, that associate with "Internet + " is not just an individual, but also see the society as a whole. Therefore, through the combination of the real economy and the Internet, the traditional industries can be guided to transform and upgrade.

\section{Challenge of "Internet +" Cultivation of Rural Entrepreneurial Talents}

The fourth education revolution in human history has come. Meeting everyone's learning needs has has been agreed. In the real education field, there are many uncoordinated and un-unified places, so the challenge of entrepreneurship education is also particularly prominent. Under the background of 
"Internet $+"$, the combination of industry and information speeds up, and the traditional industry rapidly changes to intelligent manufacturing, and the production mode is transformed from standardized production to personalized production. The repeated labor costs of traditional industries on the assembly line of will be replaced by all kinds of intelligent system, which have a significant impact to the traditional industry, and have more strict requirements for the future entrepreneurs in various aspects. How to integrate the new technology into the planning of education of rural entrepreneurship, and transform rural entrepreneurship education talent cultivation mode and implementation path are urgent problems.

\section{"Internet + Rural Entrepreneurship Education"}

The process of the "Internet + rural entrepreneurial education" is integration in-depth of Internet and rural entrepreneurial talent training. The facilities and driving factors of rural entrepreneurs education are Internet. This new model is to help rural entrepreneurship education to become an open system, and form an innovative talent model. The characteristic of "Internet + rural entrepreneurial education" is "user center", Which lead the idea of rural entrepreneurship education transformation to "the learners as the center". The full participation of the society and in-depth cooperation make it more suitable for the cultivation of entrepreneurial talents to meet the needs of social practice and improve the mechanism of educating peasants for innovation and entrepreneurship.

\section{"Internet +" brings development opportunities to rural entrepreneurial education}

"Internet + " bring some opportunities to rural entrepreneurship education. These opportunities are unattainable in past. "The People's Daily" is summarized four aspects of Internet + education as promote education fair, facilitate learners self learning and Education with big data service [1]. Learning is no longer limit of time and space [2]. From the perspective of education, especially rural entrepreneurship education, the opportunities brought by "Internet + " to rural entrepreneurial talents are mainly reflected in the following four aspects:

\section{Break the Limit of Time and Space}

The first important opportunity of "Internet + " for the cultivation of rural entrepreneurs is to make the education further break through limitations of physical time and space, thus realizing the learning at anytime and anywhere, that is "Ubiquitous Learning". And to a certain extent, the gap narrowed between education and learning caused by the gap between rich and poor. "Internet + " makes the schools without walls, the whole people learning and lifelong learning become reality, which has promoted the revolutionary change of the cultivation of rural entrepreneurial talents.

\section{Further Individualization of Rural Entrepreneurship Education}

"Internet + " brings second important opportunities for the cultivation of entrepreneurial talents in rural areas, which is to further individualize of entrepreneurship education. Benefited from the rapid rise of large data technology and learning analysis technology, entrepreneurship educational can use the big data of the Internet to develop the internet education in the direction of personalized and mobile. Especially with the continuous development of big data technology and learning analysis technology, entrepreneurship educational have more possibilities to providing more personalized services for customers. For example, using large network data, educational technology companies can develop personalized and useful personalized network teaching systems and products to meet the needs of individual learners and the needs of different types entrepreneurs. The personalization brought by "Internet + " to rural entrepreneurial talents is mainly embodied in Adaptive Learning. Adaptive Learning means that educators provide corresponding learning environments, examples or fields to learners, and learners find a summary in their own learning, and finally form a learning method to solve problems independently. In the "Internet + " era, teachers can help learners develop adaptive learning more effectively by learning personality characteristics, learning process and learning results through large data. 


\section{Model of Rural Entrepreneurship Education has Became more Pluralistic}

That "Internet +" brings the third opportunity for the cultivation of rural entrepreneurial talents is to make the entrepreneurial education breaking through the tangible restrictions of the traditional mode, so that the industrial chain of entrepreneurship education is extended, completed and refined. In the "Internet + " era, virtual schools such as cloud end schools and mobile schools have sprung up. Especially the vigorous development of MOOC has made a strong impact on the traditional entrepreneurial education model. With the increasing development of "Internet + " era, regional network and information and communication technology (ICT), the use of the Internet has been quite popular. Virtual libraries, virtual laboratories and virtual campus have also made remarkable progress. With the help of "Internet +", the teaching hardware of virtual entrepreneurship education is virtual, the teaching process is network, the teaching material is multimedia, the teaching management is remote control, and the learners become individualized.

\section{More Transformation of Rural Entrepreneurship Education Ecological}

"Internet +" will also greatly change the rural entrepreneurship education ecology, and reconstruct the ecosystem gradually. Under the "Internet + ", the form of entrepreneurship education is more and more diversified, and the system of entrepreneurship education is more and more flexible. As far as the form is concerned, "Internet + education" has both the traditional entity schools and the virtual schools based on the ubiquitous learning. "Internet + " makes entrepreneurship education richer. As entrepreneurship education is no longer limited by time and space and economic constraints, as long as there is a smart phone or a computer (including desktop computers, laptops, tablets, etc.) with an inexpensive price, and a mobile communication network or cable network service, that it can be more free to accept entrepreneurship education. Ubiquitous learning is carried out on subway, automobile, ship, train, aircraft and other means of transport. At the same time, even in remote villages and herdsmen, people who are eager to learn can enjoy all kinds of benefits brought by "Internet +" to entrepreneurship education at anytime and anywhere.

\section{"Internet +" to promote reform of Rural Entrepreneurship Education}

\section{Reform Environment of Rural Wisdom Education}

Digital environment of "Interne+"is an intelligent growth environment based on cloud computing, pervasive computing, semantic web and networking intelligent information technology. The content, activities, information resources of rural entrepreneurship education has changed by the digital transformation of people oriented. The system should be balanced through the integration of technology and education to optimize the learners' learning and teaching of trainers. Big data and learning analysis technology provide important technical support for the construction of intelligent learning environment, and it is also the key to realize personalized and differentiated teaching. the digitalization and interconnection of whole learning process has realized by the intelligent learning environment, which include the environment (including equipment, classrooms, etc.), resources (such as books, lecture notes, courseware and so on), activities (including teaching, learning, management, service, office and so on)[3].

\section{Design the Curriculum System of Rural Entrepreneurship with Systematic Thought}

System thought treats everything as a system. The system consists of two or more than two elements, and there is information output and input relationship between the outside environment and the system. [4] According to system thought, entrepreneurship education in rural areas is a system. This system is closely related to the external environment of the system, and cannot exist independently from the environment. It is the foundation for the healthy development of the system to actively respond to various challenges of the environment. The premise of rural entrepreneurship education and the prerequisite of creation curriculum system are defining with the society needs. According to system theory, the structure between elements and factors is relatively stable. As the pillar of the building of the rural entrepreneurship education, the curriculum has a relatively stable structure 
which is the basic requirement. Establishing and implementing the systematic innovation and entrepreneurship education curriculum is the foundation [5]. The rural entrepreneurship education has the characteristics of universal development and key training, which aimed for all rural entrepreneurs at innovation spirit cultivation, and focused on the learners who have the potential of entrepreneurship. According to the needs of society and the physiological and psychological development of learners, it is necessary to set up a curriculum system of entrepreneurship education in rural areas.

\section{Reform of Teaching Paradigm}

In the Internet age, any learner can obtain rich information resources and a wide range of opportunities for interpersonal interaction, and will make a new orientation to the role of teachers themselves, and the teaching activities should be transformed from "teaching" to promoting "learning". The role of teachers should be transformed from knowledge initiators to providing knowledge and assistants on the basis of the individual characteristics of the learners. Teachers should become learners, facilitators, organizers and assistants of classroom teaching, and not the inculcators of knowledge. Through the effective integration of information technology in the teaching process of various disciplines to create an information teaching environment, to achieve a teaching and learning style characterized by "autonomy, inquiry and cooperation", which can not only play the leading role of teachers but also fully reflect the main body of the learners. [6]

\section{Innovation of Learning Experience}

Developing online entrepreneurship education should not only satisfy learners' actual learning needs, but also ensure learners' learning experience effect. There will be a number of innovative ways of learning based on the Internet, such as self-regulated learning, collaborative learning, socialized learning, game learning, simulation inquiry learning, and ubiquitous learning. Learning is not only in the school, in the classroom, but also on the network, and in the intelligent mobile terminal. With the help of data or cloud computing platform, the cultivation of rural talents can analysis of the learner's interest, hobbies, goals, then scientific development learning plan, simplify the learning process, improve learner' interest in learning. For example, learners can be attracted to participate in learning actively by entrepreneurship education games. The learner is unwittingly accumulating knowledge in the course of the game. At the same time, the reward mechanism of the game can fully arouse the interest of learning, stimulate the learning motivation of the learners and improve the learning effect.

\section{Development Model, Teaching model}

\section{The Development Model of Platform + Database + Social Participation}

First, system application platform of "Internet + rural entrepreneurship education" should be built, which establish a technical architecture to convenient communication between learners, occupation colleges, industries, departments and other relevant departments by using cloud systems, big data analysis techniques. This platform provides unified identity authentication for all vocational educators and it can integrate all aspects of participants' information effectively. Through the integration analysis of information, it provides the most suitable training program for peasants in terms of training direction, employment and entrepreneurship. Second, databases should be built by the technical framework of the cloud, Internet, Data terminal. They can achieve the effective combination of vocational schools, learners and other aspects, and break the restrictions of time and space, so that the scattered training and entrepreneurship data can be integrated and interconnected. A comprehensive evaluation system of big data would form by updated learning progress and assessment for peasants in a timely. The learners design the curriculum according to their own requirements, so that the training mode and direction of the learning will be customized according to the actual needs of entrepreneurship, and it is convenient for the peasants to plan their business. Third, the big data, cloud computing and network are supporting techniques of Internet + rural entrepreneurship education. To integrate the information of computing resources and storage resources into the resource pool, peasants can break through the restrictions of the environment and 
region, can access the resource center through the Internet remotely. Learn everywhere, learn anytime, and learn everyone" can be realized by the dissemination of information technology equipment. Fourth, rural entrepreneurship education is a systematic project, which requires not only the participation of peasants and trainers, but also the involvement of the whole society. Entrepreneurship education should be an open and closely related education to various entrepreneurial activities. [7] As a whole, the role players in the mode of rural entrepreneurship education should include a variety of stakeholders, such as successful entrepreneurs, small and medium enterprises, universities, government institutions, service institutions and local communities. Rural entrepreneurship education should absorb many forces to participate in education, and not only attach the limited three forces such as "industry + university + research" or "government + production + study".

\section{O2O Teaching Model}

$\mathrm{O} 2 \mathrm{O}$ mode is an education mode which was combination of online education and offline education. The using of $\mathrm{O} 2 \mathrm{O}$ mode aims sharing the best entrepreneurial education resources. With the Internet, this mode of education can cross the time and space restrictions to realize information exchange. It can combine rural educational resources with external educational resources to realize the sharing of high quality resources. The teachers of entrepreneurship education can realize teaching on the network by recording video, and the interaction between the rural learners can be realized. Decision makers, enterprises and successful entrepreneurs can achieve teaching in this way. The following models can be used: Blending Learning mode based on MOOC. In recent years, the MOOC platform has developed rapidly in the world. MOOC can provide rich online resources and courses, and also provide an opportunity for online system learning for individualized learners. Blending Learning combines the traditional classroom face to face teaching with e-Learning. Blending Learning mode based on SPOC. SPOC (Small Private Online Course) is the small-scale restricted online course, which Setting restrictive entry conditions for learners. Compared with MOOC, there are other auxiliary online or offline classes, answering questions besides online videos and exercises. [8] The combination mode of the flipped class and the micro class teaching model, in a certain degree, the combination can transfer the decision right from the teacher to the learner, which pay attention to learning rather than just teaching, focus on the development of the peasants and not only the knowledge transfer.

\section{Practice models}

Mode one is taking technical training as the center in rural entrepreneurship education. The main task is technical training for the trainees. The target of the training is the main training object of the young peasants with certain cultural basic knowledge, the veterans and the laid-off workers of the township enterprises, and the rural labor force with all the learning requirements is taken into consideration. The length of training is based on the time needed to master the technology, flexible arrangement. As far as possible: what farmers need and what rural development needs, what rural entrepreneurship education trains. It is an effective way to cultivate new farmers with technology, management, business and entrepreneurship. Mode two is taking agricultural technology extension as the center. The main task is to carry out the research and promotion of agricultural science and technology, and to provide it directly to the trainees, or to cooperate with the technical training center for the training of the trainees in the new agriculture technology. A mechanism of entrepreneurship education with integration of production, supply, marketing and research is formed. Mode three is taking market information as the center. The main task is to investigate the market information, especially the investigation of commodity supply and demand, and to provide trainees with market information consultation. The transformation of agricultural extension to connotation development could be promoted by innovated the form of rural industrial organization and improving the scientific and technological level of production and management. This mode can make full use of information resources; reduce the excessive dependence of rural economic development on natural resources, slow down the contradiction between resources and development. Mode four is the construction of rural entrepreneurship education with college students. Since 2008, China has employed more than 100 thousand college graduates to serve in rural areas. At present, the labor force of young and young 
people in rural areas is constantly shifting to cities and non-agricultural industries, and the village cadres are generally older and lower in cultural degree. In particular, there is a serious shortage of high-quality talents in the rural areas, and the urgent need for active and well-trained college students to go to employment and entrepreneurship, and to promote the rapid economic and social development of these areas.

\section{Summary}

Represented by the Internet, The new generation of information technology will spread its application in rural entrepreneurship education. The combination of the cultivation of rural entrepreneurial talents and the Internet has ushered in a new era of "Internet + rural entrepreneurship education". The new mode of "Internet + rural entrepreneurship education" has made some achievements, but to achieve the long-term development of the rural entrepreneurship education and "Internet + rural entrepreneurship education" was a very difficult task. In this situation, it is more important to study the path of "Internet + rural entrepreneurship education" and the application of model innovation. Better integration of the Internet and rural entrepreneurship education will also be the future research direction. A flexible, open and new ecological system of personalized rural entrepreneurship education would be build by to realize information sharing, data fusion, business collaboration, and intelligent service, promote the transformation and upgrading of entrepreneurship education service forms. That a new generation of information technology represented by the Internet spread application in rural entrepreneurship education create a new mode of entrepreneurship education and entrepreneurial education service supply way. The rural entrepreneurship education is a system engineering, which is not just a matter of farmers themselves, more depends on the government, universities, public service system, and many other stakeholders of the coordination and cooperation.

\section{Acknowledgment}

This research was financially supported by the National Social Science Foundation (NSSF) West Project of China under Grant 16XSH011.

\section{References}

[1] S. Zhang. "Internet +" era, education what kinds of. people's daily, 2015-04-16 (18).

[2] S. Zhang. "Internet $+"$ spawned new education to break time and space. people's daily, 2015-04-23 (18).

[3] S. Q. Yu, A. X. Wang. The Transformation Path for "Internet + Education", China Educational Technology, vol.10, 2016, pp.1-9.

[4] H. P. Zhu. The Basic Thinking and Realizing Routes of "Internet + innovative and entrepreneurship education, Modern Education Science, vol. 3, 2018, pp.118-120.

[5] H. C. Wang, J. Y. Liu. Core, difficulty and breakthrough point of College Students' innovation and Entrepreneurship Education. China Higher education, vol. Z2, 2017, pp.61-63.

[6] K. K. He. New curriculum reform, new classroom, new leap -- how to realize information technology supported foundamental structural change in the education system. Modern Distance Education Research, vol.4, 2013,pp.3-18.

[7] W. H. Mei. Analysis of entrepreneurship education policy in EU universities [J]. Education Development Research, vol. 9, 2010, pp.77- 81.

[8] J. An, C. L. Yu. Application Research of SPOC based blended learning mode in Higher Vocational Colleges. Education Modernization, vol. 14, 2016, pp. 95-99. 